\title{
GITIZEN COMPLIANCE WITH PUBLIC POLICY: THE NATIONAL MAXIMUM SPEED LAW
}

\author{
Kenneth J. Meier and David R. Morgan \\ University of Oklahoma
}

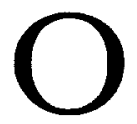

NLY RECENTLY has the study of public policy shifted its focus from the enactment of public policy to policy implementation. Since policy execution is affected by a series of economic, political, and behavioral forces, policies are as likely to fail at the implementation stage as they are at earlier stages in the process. The nation's early experience with prohibition and its more recent encounter with marijuana and other drug laws illustrates that public policies can fail because a considerable portion of the public rejects them.

The National Maximum Speed Law (NMSL) lowering speed limits to 55 miles per hour in 1974 provides an excellent opportunity to study policy compliance and noncompliance as an element of policy implementation. The NMSL is widely violated with estimates that as many as 54 percent of all vehicles nationwide exceed the speed limit (1979 figures). Since the NMSL is enforced by the states, substantial variation in enforcement and compliance exists. Compliance with the law ranges from a low of 28 percent in Texas to a high of 72 percent in Virginia (1978). Both the variation and the reasonably reliable measure of compliance make the National Maximum Speed Law an excellent case to examine reasons for policy adherence and to consider some options governments have to exact greater compliance.

This study will analyze compliance with the NMSL through several approaches. First, a theory of citizen compliance will be derived from the literature. Second, using data from all 50 states, the environmental features of the states that affect vehicular speed will be examined. Third, the impact of enforcement efforts on speed law compliance controlling for environmental characteristics will be analyzed. Fourth, the compliance of state populations with the NMSL given environmental constraints will be related to state variations in driver attitudes. Finally, the policy implications of this study will be discussed.

\section{Public Policy Complance Theory}

According to Van Meter and Van Horn (1975: 458), two key factors affect whether or not a policy is implemented: the degree of change the policy makes in the status quo and the degree of consensus on policy goals. These authors hypothesize that small changes with high consensus are easy to implement while large changes with little consensus will be difficult to implement. They feel these are the two major patterns. (The other two are high change with high consensus and low change with low consensus.)

The National Maximum Speed Law appears to be an exception to the Van Meter and Van Horn theory. The NMSL is an incremental change

NOTE: An earlier version of this paper was presented at the annual meeting of the Southern Political Science Association, Atlanta, November 6-8, 1980. 
adjusting the speed limit from 5 to $20 \mathrm{mph}$ depending on the state. ${ }^{1}$ It is also a high consensus policy; public opinion polls (Gallup, 1977) show strong support for the law. Although NMSL proposes a small change that has high consensus, lack of compliance with the law is high. This suggests that the literature on compliance be examined to find out why NMSL compliance is so low.

The study of individual compliance with public policy is a relatively recent phenomenon. The major theory and most of the studies have been developed in the area of public law, specifically on compliance with Supreme Court decisions. (Clark et al., 1972; Stover and Brown, 1975; Logan, 1975; Erickson and Gibbs, 1975; Rodgers and Bullock, 1976a, 1976b; Bullock and Rodgers, 1976.) Recently Young (1976) has generalized compliance theory to the study of international relations.

Compliance theories assume that the individual is a rational decision maker who engages in a cost-benefit analysis of compliance. A person will comply with the law if the utility of compliance exceeds the utility of noncompliance (Rodgers and Bullock, 1976a: 4; Young, 1979: 17; Stover and Brown, 1975: 370). Utilities are composed of two elements in compliance theory, benefits and costs. Therefore a person complies if

$$
\mathrm{Bc}-\mathrm{Cc}>\mathrm{Bn}-\mathrm{Cn}
$$

Where $\mathrm{Bc}$ are the benefits of compliance

Cic are the costs of compliance

$\mathrm{Bn}$ are the benefits of noncompliance

Cn are the costs of noncompliance

If the utility of complying (benefits minus costs) exceeds the utility of not complying (benefits minus costs), a person will comply with the law. If it does not, a person will not comply. An individual's decision on compliance is, of course, based on perceptions of benefits and costs. Some individuals will consider some benefits more important than will other individuals while other people will stress certain costs more. Two persons with the same real costs and benefits may well make different decisions because they perceive the benefits and costs differently.

Compliance theory then leaves benefits and costs to focus on the factors that affect perceptions of benefits and costs. Rodgers and Bullock (1976a: 5) in their study of compliance with school desegregation orders list eight factors affecting the calculus: (1) the clarity of the law; (2) certainty and severity of punishment; (3) perceived legitimacy of the law; (4) demands for enforcement; (5) agreement with the policy; (6) ability to measure compliance; (7) extent of monitoring; and (8) the existence of an enforcement agency. To these reasons Anderson (1975) adds self-interest, indifference, peer group pressure, and law-value conflicts. Young (1979: 24) adds habit as a reason for compliance. Although the number of explanatory variables is

${ }^{1}$ Although some might argue that a speed reduction of $20 \mathrm{mph}$ or 27 percent is not incremental, we disagree. John J. Bailey and Robert O'Conner (1975: 64) define non-incremental as changes of more than 30 percent. In addition, the NMSL should be considered incremental when compared to other considered policy options such as gasoline rationing or a $35 \mathrm{mph}$ speed limit. 
impressive, we feel that they can be grouped into three factors: environment, enforcement, and attitudes. Each of these will be discussed in turn with specific reference to the National Maximum Speed Law.

\section{Environment}

The above list of factors influencing the compliance calculus does not specifically mention environment (but see Bullock and Rodgers, 1976). This omission is understandable in one sense; because environments change slowly, they may not seem to exert an immediately obvious force. But the environment indeed may substantially affect the opportunity for compliance. For example, persons living in small midwestern towns may not have the opportunity to violate a pornography or prostitution law. A small businessman may never have the chance to fix prices. Opportunities for noncompliance, a necessary condition for noncompliance, are thus often a function of the environment, which may be thought to include the physical, economic, social, and political setting.

In the specific case of the National Maximum Speed Law, environmental conditions affect the cost-benefit calculus in two ways. First, congested roads may physically prevent speeds in excess of $55 \mathrm{mph}$. In this case the environment forecloses the opportunity for noncompliance. Second, precipitation and other factors may increase the costs of noncompliance by increasing the risk of fatal accidents. In this case, the environment changes the values of the costs and benefits.

One frequently mentioned reason for compliance, the clarity of the law, is also an environmental factor (Rodgers and Bullock, 1976a: 5; Anderson, 1975). ${ }^{2}$ When policy is complex or ambiguous, many people will not comply because they do not know what specifically the law is. Many provisions of the Tax Code could be cited as examples. The ambiguity of the law, however, does not apply to the NMSL. State and federal laws are clear on this question-driving faster than $55 \mathrm{mph}$ is illegal. Given the public relations campaigns by the federal and state governments plus the number of speed limit signs, the percentage of drivers who are unaware of this law must be small indeed.

\section{Citizen Attitudes}

Attitudes toward the law are a second major cluster of variables that affect compliance with public policy. Respect for government, belief that government is the legitimate arbiter of public policy, conscious acceptance of the law, law-value conflicts, and agreement with the policy are attitudinal explanations of policy compliance. Anderson (1975), Young (1979), Rodgers and Bullock (1976a), and Stover and Brown (1975) all argue that persons rejecting a policy or government's legitimacy in making that policy affect compliance. As Robert Dahl (1956) notes in another context, attitudes are always the initial check on behavior.

Clearly some of the variation in the NMSL compliance should be explained by variations in individuals' attitudes toward the NMSL and the

${ }^{2}$ If more states follow the recent Nevada effort to limit speeding fines to $\$ 5.00$ if the vehicle was under $70 \mathrm{mph}$, clarity may become a factor. 
government that enacted it. For example, the 1978 Wyoming effort to raise the speed limit was couched in antifederal rhetoric. A New Mexico study reveals a strong relationship between the belief that the law added an unreasonable amount to driving time and stated failure to comply with the law. Frequent violators also felt the law should not be enforced (Sievers, 1977: 20).

In general, however, national surveys (Gallup, 1977) show support for the $55 \mathrm{mph}$ limit even in the South and West where noncompliance is high. As a result, disagreement with the policy cannot explain the full extent of noncompliance. This situation is not uncommon. Boynton et al. (1978) found that only 3 percent of the population felt a person should disobey a law that he or she personally opposed. Another survey, however, revealed that 91 percent of the population admitted to violating a criminal law at some time during their lives (The Challenge of Crime, 1967).

Self-Interest. Self-interest is often cited as a reason for compliance with the law (Anderson, 1975). The calculus of compliance is, of course, based on perceptions of those benefits and costs affecting one's interests. In this case, the particular ways in which the NMSL might influence a person's perceived self-interest should be specified. Those who feel the price of gasoline is too high (72 percent), or that higher speeds result in more deaths (71 percent), might consider compliance with the NMSL to be in their own selfinterest (Comptroller General, 1977: 17). Individuals who believe that the cost in lost time of the NMSL is excessive might argue their self-interest dictates noncompliance (Castle, 1976). We assume the more a person travels the greater the time cost versus the other cost and, therefore, the greater the likelihood of noncompliance. Some evidence exists to support this hypothesis. The New Mexico survey shows that people who travel a great deal also violate the speed law more often. In addition, commuters and occupational drivers violate the NMSL more than recreational drivers do (Sievers, 1977: 21). ${ }^{3}$

Peer Pressure. Peer pressure to ignore a law may arise when a person belongs to groups that routinely violate the law. A college student with friends that smoke marijuana may well also violate the law because others do. A dry community that has openly operating bars encourages noncompliance. Peer pressure is a concern with the loss of social rewards-status, friendship, acceptance, time - that might result from nonconformity. This nonconformity may result in attitudes hostile to or at least indifferent to the law. A process similar to peer pressure happens with the NMSL. In a state such as Texas where 72 percent of all vehicles violate the law, the normal driver might also choose to speed. Rationally the driver knows that not everyone can be arrested if violations are rampant, and the driver may even realize that he/she is safer driving with the flow of traffic than driving 55 mph (California Highway Patrol, 1974). Although peer pressure's influence on attitudes may well explain noncompliance at the individual level, at the

${ }^{3}$ Self-interest, therefore, contains both attitude and environmental factors. Since self-interest is inherent in the compliance calculus, a set of variables will not be introduced. 
aggregate level it becomes tautological, i.e., state $\mathrm{X}$ has more people speeding because people see other people speeding.

\section{Enforcement}

Some people comply with public policy because they fear punishment if they are caught. In cost-benefit terms, enforcement increases the costs of noncompliance. Anderson (1975), however, argues that the real deterrent value of punishment is in reinforcing the other reasons for compliance. ${ }^{4}$ Punishment of the most flagrant violators serves as an example to those considering noncompliance. Enforcement encompasses a host of variables such as certainty of punishment, severity of punishment, existence of an enforcement mechanism, clarity of measurement of compliance, and extent of monitoring.

The literature shows enforcement to be a major influence. Rodgers and Bullock (1976a: 165) find that strong enforcement is the major explanation of school desegregation in 31 Georgia school districts. The public law literature generally finds that the probability of being sanctioned is more important than the size of the penalty in exacting compliance (Tittle and Rowe, 1974; Salem and Bowers, 1972; Logan, 1975; Erickson and Gibbs, 1975).

In regard to the NMSL, enforcement is perceived to be a major factor in compliance. The federal government has charged several states with failure to enforce the law using noncompliance figures as an indicator. The New Mexico survey reveals that strict enforcement is the major reason people cite for complying with the NMSL. Over 43 percent felt strict enforcement would cause them to comply. This percentage is four times the percentage for the next most important reason (price of gasoline, see Sievers, 1977).

\section{Compliance Theory: A Summary}

Individual compliance with public policy according to our theory is based on an individual assessment of the costs and benefits of compliance and noncompliance. The compliance calculus is affected by three sets of variables-the environment, individual attitudes, and enforcement. Factors in the environment facilitate or inhibit compliance or noncompliance. Individual attitudes affect the perceived benefits and cost of compliance and noncompliance. ${ }^{5}$ The remaining sections of the paper will analyze the impact of these three basic forces on compliance with the NMSL. Although our theory suggests that environmental, enforcement, and attitude variables should all be considered simultaneously, from a policy perspective each type of variable needs to be treated separately. Policy-makers need to consider what

\footnotetext{
${ }^{4}$ We will use the term enforcement to refer only to the physical act of enforcement. No attempt will be made to measure at titudes toward enforcement or punishment.

${ }^{5}$ The compliance theory outlined here is similar to the incentive theories of Etzioni (1961) and Wilson (1973). The basic cost and benefit calculus of compliance/noncompliance relates directly to utilitarian incentives for compliance. Individual attitudes affect the cost and benefit values similar to the normative incentives of Etzioni. Wilson's solidary incentives are incorporated somewhat in peer pressure. Our conception of enforcement is broader than Etzioni's since it encompasses more than just physical coercion.
} 
is given, what can be changed, and what can be influenced only indirectly. Environmental variables are not only given, they impose constraints within which the other two influences must operate. Environment should be analyzed first. Enforcement variables are under the control of state officials; they need to be considered next. Finally, the state can affect citizen attitudes only over time; the attitude variables will be examined last.

\section{A Preliminary Analysis of Differences by State}

Compliance theory as applied to the specific case of the $55 \mathrm{mph}$ speed limit suggests six possible environmental variables that may explain noncompliance. First, the amount of driving the average resident does (measured as vehicle miles traveled per capita) should be positively associated with noncompliance. The more miles driven per year, the more likely a driver will have opportunities to exceed the speed limit. Second, the size of the state (measured in square miles) should be positively associated with noncompliance. Larger states generally correspond to greater distances between cities and, therefore, their residents may perceive some self-interest in faster speeds. ${ }^{6}$ Third, the percentage of interstate highways should be positively related to noncompliance. Wide four-lane, limited access highways provide drivers more opportunities to exceed the speed limit than twolane highways. Fourth, the number of days of precipitation a state receives should be negatively correlated with noncompliance. ${ }^{7}$ Rain, snow, and ice make high speed driving dangerous and, therefore, limit the driver's opportunity for noncompliance. Fifth, altitude variation within a state should be negatively associated with noncompliance. State roads must reflect terrain. In a state with a great deal of variation, roads are more apt to be narrow and contain more hills and curves; all these factors slow traffic. Sixth, the minimum legal driving age in a state should be negatively related to noncompliance. Younger drivers tend to drive faster.

These six environmental variables are, with the exception of the minimum driving age, outside the control of the state. To the extent that these variables explain a large portion of the variation in noncompliance, they illustrate the relative difficulty in enforcing the NMSL in different states. A state that is small, has few interstates, has much precipitation, has substantial variation in altitude, has a high minimum driving age, and has residents who drive little should have less noncompliance. Such a state may well enforce the NMSL less yet show better results than a state with less favorable environmental characteristics.

Two measures of compliance will be used in this study-the percentage of drivers exceeding $55 \mathrm{mph}$ and the 85 th percentile speed of all vehicles for

\footnotetext{
${ }^{6}$ The size measure is a surrogate variable. Creating a measure of distance between major population areas was handicapped by two factors. First, definition of a population center is not unambiguous. Second, in many cases urban areas or SMSAs are contiguous so no clear demarkation of major population centers exists. Percent urbanization was also used as an indicator, but it was unrelated to compliance.

${ }^{7}$ Both days of precipitation and inches of precipitation work equally well as predictors. Days of ice and snow do not predict compliance well; we suspect this is because drivers in cold weather states adapt well to snow cover on the roadway.
} 
$1978 .{ }^{8}$ The first measure is a direct indicator of noncompliance adopted by the federal government and, therefore, is not controversial from a substantive perspective. It does have some weaknesses. In a state where motorists consistently exceed the speed limit by a few miles per hour, a large noncompliance figure will result. ${ }^{9}$ Where measured as percentage over $55 \mathrm{mph}$, this situation will be indistinguishable from a state where the free flow traffic exceeds $65 \mathrm{mph}$. In short, the first noncompliance measure does not distinguish between minor noncompliance and gross disregard for the law. The second measure, the 85th percentile speed, taps this more extreme variation. ${ }^{10}$

Table 1. Predicting Noncompliance with the National Maximum Speed LaW (1978) Using ENVIRONMENTAL VARIABLES

\begin{tabular}{|c|c|c|c|c|}
\hline \multirow[b]{3}{*}{ Independent Variable } & \multicolumn{4}{|c|}{ Noncompliance Measure } \\
\hline & \multicolumn{2}{|c|}{$\%$ Exceeding $55 \mathrm{mph}$} & \multicolumn{2}{|c|}{ 85th Percentile Speed } \\
\hline & Slope* & $t$ & Slope ${ }^{*}$ & $t$ \\
\hline Miles Driven Per Capita & .26 & 1.87 & .31 & 2.63 \\
\hline Size of State & .34 & 1.85 & .48 & 3.21 \\
\hline Interstate Highways (\%) & .34 & 2.50 & .41 & 3.55 \\
\hline Days of Precipitation & -.25 & 1.80 & -.42 & 3.68 \\
\hline Altitude Variation & -.47 & 2.83 & -.49 & 3.57 \\
\hline \multirow[t]{2}{*}{ Minimum Driving Age } & -.21 & 1.62 & -.17 & 1.59 \\
\hline & $\mathrm{R}^{2}=.39$ & & $\mathrm{R}^{2}=.58$ & \\
\hline
\end{tabular}

* Standardized regression coefficients.

Regression results for the two independent variables are shown in Table 1. For the percent exceeding $55 \mathrm{mph}$ measure, the level of prediction is fairly modest $\left(\mathrm{R}^{2}=.39\right)$. All the relationships are in the hypothesized direction. The most important restraint appears to be altitude variation. ${ }^{11} \mathrm{~A}$ large percentage of interstate highways and the size of the state are the

${ }^{8}$ All vehicles (automobiles and trucks) are included in these two measures, although the data are taken only from rural interstate highways.

${ }^{9}$ The $55 \mathrm{mph}$ compliance figure may also be high because of informal decision rules used by highway patrol. One state operates under the rule of thumb "warn at $60 \mathrm{mph}$ and ticket at 65 ." Its concern is the high speed driver, those reflected in the $85 \mathrm{th}$ percentile measure.

${ }^{10}$ The 85 th percentile speed is not an arbitrary figure. In the days before the NMSL, traffic safety rules of thumb suggested that the speed limit be set at the 85 th percentile of all vehicle speeds on a stretch of highway. Setting the speed limit at this level generated the tightest distribution of speeds and, therefore, contributed to traffic safety.

${ }^{11}$ Altitude is measured as the actual range from the lowest point in the state to the highest point. Although this is an imperfect measure, it does reflect variation in terrain. Colorado, a mountainous state, has a range of 11,083 feet while Kansas, a relatively flat state, has a range of only 3,359 feet. 
second most important predictors with driving age, miles driven, and precipitation all relatively equal in influence.

The relationship between environmental variables and noncompliance is clearer for the 85th percentile speed. The six environmental measures explain 58 percent of the variance in the 85 th percentile speeds. Four variables have strong and relatively equal effects-precipitation, altitude variation, interstate highways, and state size. Miles driven per capita has a more modest impact while minimum driving age is only weakly related to speed. All relationships are in the hypothesized direction.

\section{Examining Deviant States}

Table 2 shows the residuals for both multiple regressions in Table 1. Since the meaning of the residuals is not self-evident, an illustration is in order. For the state of Washington, the regression predicts that 37.8 percent of all vehicles will exceed the $55 \mathrm{mph}$ speed limit. The actual noncompliance percentage is 56.7 , leaving a residual of +18.9 percent (this figure appears in column 1 of Table 2). Substantively, the state of Washington has 18.9 percent more vehicles violating the $55 \mathrm{mph}$ speed limit than would be expected given the state's minimum driving age, miles driven, precipitation, altitude variation, interstates, and size. In short, Washington does significantly worse than expected given its environmental constraints. Column 3 of Table 2 contains the residuals for the 85 th percentile regression. To illustrate, the predicted 85 th percentile speed for Washington is $58.58 \mathrm{mph}$ while its actual 85th percentile speed is $60.00 \mathrm{mph}$. The residual, thus, indicates that Washington's 85th percentile speed is $1.43 \mathrm{mph}$ faster than environmental variables suggest.

Given the federal pressures on states for greater enforcement, the residuals have policy implications. The state of Wyoming, for example, has received substantial criticism for its noncompliance. Its noncompliance figure for 1978 was 74 percent, and its 85 th percentile speed was $64.9 \mathrm{mph}$. But both figures are slightly less than the environmental variables would predict. In short, Wyoming can argue that its compliance record with the NMSL is slightly better than average when its unique environment is considered.

The residuals are a better measure of state efforts for compliance than the raw compliance figures. At the present time, some states are being given credit for good compliance records simply because environmental conditions make it difficult to speed.

\section{ENFORCEMENT AND COMPLIANCE}

Federal pressure to improve compliance with the NMSL is based primarily on the deterrent effect of enforcement. Greater enforcement, indicated by more speeding citations issued, should reduce noncompliance with the NMSL. When an enforcement measure (speeding citations per 1,000 population) is added to the above multiple regression equations, the results are surprising. Although enforcement has a significant relationship to com- 
TABLE 2. Residuals-Noncompliance with SPeEd LaW and ENVIRONMEntal Variables

\begin{tabular}{|c|c|c|c|c|}
\hline \multirow[b]{2}{*}{ State } & \multicolumn{4}{|c|}{ Residuals } \\
\hline & $\%$ Exceeding $55 \mathrm{mph}$ & Rank & 85th Percentile & Rank \\
\hline Washington & 18.9 & 1 & 1.42 & 6 \\
\hline Connecticut & 11.7 & 2.5 & 1.34 & 9 \\
\hline Vermont & 11.7 & 2.5 & 1.40 & 7.5 \\
\hline Texas & 11.5 & 4 & 2.86 & 1 \\
\hline Kansas & 10.5 & 5 & .07 & 29 \\
\hline Missouri & 8.3 & 6 & .34 & 21 \\
\hline Indiana & 7.6 & 7 & .37 & 19 \\
\hline Delaware & 6.9 & 8 & 1.44 & 4.5 \\
\hline Nevada & 6.6 & 9 & 1.44 & 4.5 \\
\hline Maine & 6.5 & 10 & 1.40 & 7.5 \\
\hline Oregon & 4.7 & 11 & .32 & 22 \\
\hline Iowa & 4.4 & 12 & .09 & 28 \\
\hline North Carolina & 4.2 & 13.5 & -.61 & 36 \\
\hline Ohio & 4.2 & 13.5 & .27 & 23 \\
\hline South Carolina & 3.9 & 15 & -1.16 & 42 \\
\hline Nebraska & 3.8 & 16 & -.46 & 35 \\
\hline West Virginia & 3.5 & 17 & .36 & 20 \\
\hline Utah & 3.3 & 18 & -.42 & 34 \\
\hline Montana & 3.0 & 19 & .93 & 11 \\
\hline Minnesota & 2.6 & 20 & -.83 & 40 \\
\hline Georgia & 2.5 & 21 & .96 & 10 \\
\hline Arizona & 1.9 & 22 & -.30 & 33 \\
\hline Rhode Island & 1.7 & 23.5 & .66 & 14 \\
\hline Wisconsin & 1.7 & 23.5 & .20 & 27 \\
\hline North Dakota & 1.3 & 25 & .66 & 14 \\
\hline Mississippi & .8 & 26 & .38 & 18 \\
\hline California & .3 & 27 & -.69 & 38 \\
\hline Illinois & .0 & 28 & .44 & 17 \\
\hline New Hampshire & -.1 & 29 & .49 & 16 \\
\hline Maryland & -.5 & 30.5 & -.26 & 32 \\
\hline Arkansas & -.5 & 30.5 & 1.52 & 3 \\
\hline Michigan & -1.2 & 32.5 & .22 & 26 \\
\hline Wyoming & -1.2 & 32.5 & -1.07 & 41 \\
\hline Alabama & -1.7 & 34 & .25 & 24.5 \\
\hline New York & -2.3 & 35 & .25 & 24.5 \\
\hline Massachusetts & -2.9 & 36 & -.19 & 31 \\
\hline Pennsylvania & -4.7 & 37 & -1.39 & 45 \\
\hline Oklahoma & -5.1 & 38 & -.67 & 37 \\
\hline Alaska & -5.4 & 39.5 & -.79 & 39 \\
\hline Florida & -5.4 & 39.5 & .06 & 30 \\
\hline Colorado & -5.6 & 41.5 & -1.36 & 44 \\
\hline New Mexico & -5.6 & 41.5 & .66 & 14 \\
\hline New Jersey & -6.0 & 43 & -1.79 & 48 \\
\hline South Dakota & -6.2 & 44 & -1.27 & 43 \\
\hline Hawaii & -7.1 & 45 & .72 & 12 \\
\hline Idaho & -8.6 & 46 & -1.44 & 46 \\
\hline Tennessee & -9.7 & 47 & 1.95 & 2 \\
\hline Louisiana & -17.5 & 48 & -2.48 & 49 \\
\hline Kentucky & -22.7 & 49 & -1.78 & 47 \\
\hline Virginia & -27.6 & 50 & -4.52 & 50 \\
\hline
\end{tabular}


pliance with the NMSL, the effect is positive. ${ }^{12}$ Greater enforcement is associated with greater noncompliance-exactly opposite of the theoretical prediction. For the 85th percentile measure of compliance, enforcement has almost no impact, but even the little influence enforcement has is in the wrong direction. ${ }^{13}$

The unanticipated direction of the relationship between enforcement and compliance suggests that the simple correlation between the two measures be examined. The simple correlation between noncompliance with the NMSL and enforcement of the law (citations per capita) is .46 for 1978. This positive relationship between noncompliance and enforcement holds for both $1976(\mathrm{r}=.37)$ and $1977(\mathrm{r}=.38)$ and appears to hold for $1979(\mathrm{r}=.38)$. Even different measures of enforcement do not change this relationship. ${ }^{14}$

The positive relationship between noncompliance and enforcement requires comment. Clearly greater enforcement does not cause people to drive faster. What the empirical correlation reveals is a demand relationship. As speeds increase, police write more speeding tickets. This is similar to the relationship between crime rates and crime expenditures (see Jones, 1973). Enforcement responds to noncompliance, not vice versa.

The demand relationship should not be taken to indicate, however, that enforcement cannot limit speeds and, therefore, states should not be required to enforce the law. The scatterplot of the data (not shown) reveals that the relationship between noncompliance and enforcement is not strictly linear. As enforcement rises, speed increases at a decreaasing rate. If enforcement is increased to a sufficiently high level, speeds should drop because punishment would be more certain. Substantively this makes sense; if highway patrol cars could be placed every half mile on all roads, and all apprehended violators were ticketed, eventually compliance would be close to total.

Empirically this relationship between compliance and enforcement is summarized by the line in Figure 1. The line (estimated from actual data)

${ }^{12}$ Three other enforcement measures were also included in a preliminary analysis-maximum fine, maximum jail sentence, and maximum number of points that could be lost toward license revocation for a speeding violation. None of these severity of punishment variables contributed to explained variance when environmental variables were included in the regression equations. This finding is consistent with the crime control findings that certainty of arrest, not severity of punishment, is the major deterrent.

${ }^{13}$ Since the enforcement measure affected compliance in the "wrong" direction (it has a positive impact, indicating that more tickets lead to higher speeds), it will be deleted from further regression analyses. Because enforcement responds to noncompliance using enforcement as an "explanatory" variable violates the causal assumptions of our theory. Enforcement's positive relationship with noncompliance holds both at the simple level and subject to controls. Nonetheless, if the speeding citations per 1,000 population had been included, it would have increased $R^{2}$ by .03 for the $55 \mathrm{mph}$ compliance measure and by .01 for the 85 th percentile variable. The correlation between the enforcement measure and the residuals in Table 2 was less than .05 in both cases.

${ }^{14}$ Two other measures of enforcement were tried: citations per mile driven and citations per licensed driver. The correlations between those two measures and the two compliance measures were positive, ranging from 39 to .50 . We used citations per capita because it is the figure used by the federal government in assessing enforcement effort. The other measures lack this policy relevance. In any case, the selection of enforcement measure does not substantively change the findings. All four citation measures are intercorrelated at over .95 . 
suggests that enforcement will not reduce the percentage of drivers who fail to comply with the NMSL until approximately 200 citations per 1,000 population are issued. Enforcement above this level should gradually reduce the amount of noncompliance. Although the cirvilinear regression line in Figure 1 is based on actual 1978 data, our argument must remain speculative since no states issue more that 215 tickets per 1,000 population. In fact, Wyoming the enforcement leader, is a deviant case; the next greatest enforcement level is approximately half of Wyoming's rate, and the mean enforcement rate is only 48 citations per 1,000 population.

FIGURE 1. Relationship Between Enforcement and Compliance

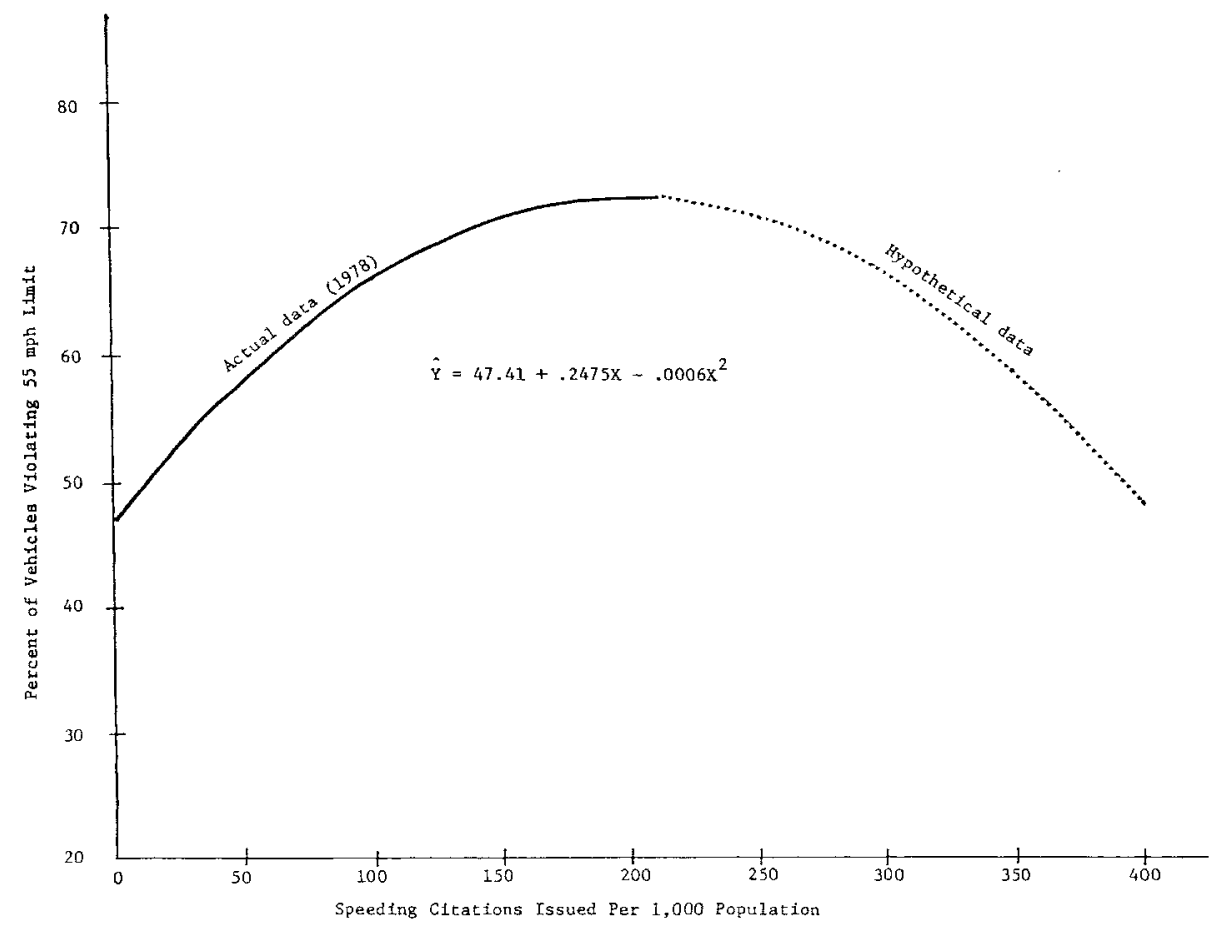

The policy question raised by the graph in Figure 1 is this: if a state provides the environmental opportunities for speeding, is it politically and economically feasible for that state to enforce the NMSL at a level that will actually reduce speeds? A level of enforcement of 550 tickets per 1,000 people might be required to gain full compliance with the NMSL according to the equation in Figure 1. This level of enforcement is 11 times that of the average state. Although the result would be many lives saved, the cost would be fairly high. At the marginal expenditure level, a state might find it less expensive to forego federal highway funds than to enforce at this level. In addition, the political ramifications of writing speeding tickets to 55 percent 
of a state's population (or even giving that many tickets to tourists passing through) are not known. People may not tolerate enforcement at that level just as they probably would not tolerate the IRS auditing everyone every year.

\section{AtTitudes AND NONCOMPLiAnCE}

Although state environmental variables account for a large portion of the variation in noncompliance with the NMSL, the explanation is far from total. Even without enforcement measures, 61 percent of the variation in state compliance with the NMSL and 42 percent of the variation in 85 th percentile speeds remain unexplained. The most promising set of variables remaining from the perspective of compliance theory are individual attitudes. Value-policy conflicts and self-interest both have their roots in individual attitudes. Individuals whose attitudes do not support the NMSL are not likely to comply with the law. And individuals who perceive their self-interest does not coincide with the NMSL are also likely violators.

Unfortunately for any analysis of state compliance with the NMSL, good measures of individual attitudes aggregated at the state level do not exist. Most surveys either cover a single state or are national in origin. In the latter case, insufficient respondents are contained for each state to permit any inferences about attitudes within a state. Despite the absence of reliable data, some attempt should be made to measure driver attitudes. Citizen attitudes play a crucial role in our compliance theory and in most other compliance theories. To omit an attempt to incorporate these variables, however imperfectly measured, would leave a major theoretical void. To resolve the absence of good data, several surrogate measures of opinion will be created for all 50 states including estimated attitudes toward the NMSL, state political culture, past driver behavior, and the price of gasoline.

"Estimated attitudes" toward the NMSL will be measured by the results of a Gallup poll question "Do you favor or oppose keeping the present 55 mile-per-hour limit on the highways of the nation?" adjusted for each state by the Kim et al. (1976) technique. State political culture is operationalized as Elazar's (1972) traditionalistic political culture, a culture likely to support policy even if it lacks public support. ${ }^{15}$ Past driver behavior is operationalized as the state's pre-NMSL speed limit. ${ }^{16}$ The price of gasoline, an indicator of self-interest in lower speeds, was taken from American Automobile Association records.

${ }^{15}$ Political culture is coded from Elazar's map as a dummy variable with " 1 " coded if traditionalistic was the dominant culture in the state. Political culture and the operationization of it used here has been criticized. Culture has been criticized as a reification; that it is nothing more than a collection of political attitudes. We do not dispute this objection. In fact, political culture in this study is used as a surrogate variable for political attitudes concerning the legitimacy of the NMSL. If we had direct measures of these attitudes, we would use them. The next best approach is to include several indirect measures of the attitudes, the technique used here.

${ }^{16}$ States with such speed limits as "reasonable and proper" were coded at 80 mph since no state had a higher limit than $75 \mathrm{mph}$. The highest speed limit in each state was used, usually the one for rural interstates. This might overestimate speeds in urbanized states, but such states generally had lower speed limits than more rural states. The range of this measure is from $50 \mathrm{mph}$ to $80 \mathrm{mph}$. 


\section{The Effects of Attitudes}

The simple correlations between the attitudinal indicators and NMSL compliance are not high. Only one of the surrogate attitudinal measures is related to compliance with the NMSL-driver behavior operationalized as the pre-1973 state speed limits. At the simple level estimated attitudes, traditionalistic culture, and the price of gasoline are unrelated to compliance with the speed law. ${ }^{17}$

Driver attitudes do not operate in a vacuum, however. Attitudes operate in the context of the environmental characteristics of the state. Table 3 shows the relationship between each of the attitudinal measures and the two compliance measures controlling for environmental features. For the percent violating the $55 \mathrm{mph}$ speed limit, traditional political culture, as predicted, is negatively related to noncompliance. In fact, inclusion of traditional political culture adds 5 percent additional explained variance to the model. Estimated attitudes, gas price, and past speed limit add less than 1 percent explanation.

For 85th percentile speed, the estimated attitude toward the NMSL is the only variable with any impact. Even the estimated state attitude, how-

TABLE 3. Standardized Regression COefFicients fOR Compliance and Driver Attitudes Controlling for EnVironmental Variables*

\begin{tabular}{|c|c|c|c|c|}
\hline \multirow[b]{3}{*}{ Attitude Measure } & \multicolumn{4}{|c|}{ Noncompliance Measure } \\
\hline & \multicolumn{2}{|c|}{$\%$ Exceeding $55 \mathrm{mph}$} & \multicolumn{2}{|c|}{ 85th Percentile Speed } \\
\hline & Slope** & $t$ & Slope ** & $t$ \\
\hline Simulated Attitude & .22 & 1.32 & .18 & 1.34 \\
\hline Political Culture & -.25 & 2.03 & -.05 & .44 \\
\hline Driver Behavior & .05 & .33 & .07 & .48 \\
\hline Gasoline Price & .05 & .36 & -.01 & .13 \\
\hline
\end{tabular}

*Controlling for state size, interstate highways, miles driven, altitude variation, precipitation, and minimum driving age.

**Slopes for variables as if they were the only variable added to the regression equation, often called Beta-in.

${ }^{17}$ The simple correlations follow:

Noncompliance Measure

Attitude Measure

Simulated Attitude

Political Culture

Driver Behavior

Gasoline Price $(\mathrm{N}=48)$
\% Exceeding $55 \mathrm{mph}$

85th Percentile Speed

$\begin{array}{rr}.02 & -.10 \\ -.06 & .15 \\ .37 & .49 \\ .01 & -.08\end{array}$


ever, adds less than 2 percent additional explained variation. Substantively this amount is hardly significant. Culture, prior speed limits, and gasoline price are unrelated when environment is controlled.

\section{SUMMARY Discussion}

Using public policy compliance theory, this research has sought to identify those forces responsible for the variation among states in adhering to the National Maximum Speed Law (NMSL). Initially an assumption was made that environmental factors would constitute a major limitation on excessive speed. Indeed we found that altitude variations among the states, the proportion of interstate highways, and the size of the state were important determinants of both the percentage exceeding $55 \mathrm{mph}$ and the 85th percentile speed. Enforcement was then considered on the assumption that fear of punishment would induce compliance. It was not so. In fact, as the number of tickets increased, vehicle speed also increased. Clearly this is a case of enforcement responding to noncompliance and not vice versa. Evidence suggests, however, that if enforcement levels were sufficiently high, speeds should decline.

Following this analysis of environmental and enforcement effects, attitudes were considered. Assuming that behavior follows attitudes, several surrogate measures of public opinion toward the $55 \mathrm{mph}$ speed law were incorporated in the analysis. All were relatively indirect indicators, and the results were disappointing. When environmental variables were controlled, only a traditionalistic political culture was of any consequence (solely for percentage exceeding $55 \mathrm{mph}$ ). Obviously the attempt to locate appropriate attitudinal measures at the state level was not satisfactory. Yet we assume at the individual level a strong correspondence exists between a person's view of the speed law and his or her unwillingness to comply. Somehow when these individual-level measures are aggregated to the state level the relationship significantly attenuates. Future efforts to improve state-level attitude measures cannot but be fruitful.

A comment on the policy implications of this research seems in order. The federal government possesses a powerful incentive to compel states to adhere to the maximum speed law-the threat to cut off federal highway funds. Even though this penalty has yet to be invoked, the Department of Transportation (DOT) regularly monitors state compliance and periodically issues warnings. The DOT compliance figures do not take account of the "natural" limitations on speeding that exist among some states. So, as noted here, such states as Wyoming appear to be consistent violators, when in fact these states may be making a determined effort to enforce the law. Other states, such as Washington or Vermont, may be able to achieve compliance with much less difficulty. An argument surely can be made that before any drastic federal action is taken against any state, consideration should be given to the various external conditions, such as those identified here, that obviously affect compliance.

This analysis of the NMSL should not be taken to imply the law is a failure. Enactment of the law resulted in a national drop of $8 \mathrm{mph}$ in vehicle 
speeds. Billions of gallons of gasoline and thousands of lives were saved. Full compliance, a problem facing many intergovernmental efforts such as pollution control, integrated housing, and school desegregation, would bring additional benefits. Somehow the federal government or the states need to consider environmental constraints and provide greater incentives for citizen compliance.

\section{IMPLICATIONS FOR COMPLIANGE THEORY}

The findings of this paper have three implications for compliance theory as it relates to public policy. First, environmental variables strongly affected compliance. As a result, future theoretical efforts should explicitly include environmental constraints as a major theoretical factor. Variation in these conditions will likely affect the degree of compliance.

Second, enforcement was not a major factor in explaining compliance. In fact, enforcement was associated with noncompliance. What distinguishes this finding from the school desegregation findings and crime control findings that show some enforcement impact? The findings of Bullock and Rodgers (1976) are easily distinguished from these. They were dealing with a finite number of school districts and sufficient personnel to monitor every district. The probability of apprehension was very high. In the NMSL instance, the probability of apprehension was fairly small. (.048 for an entire year). The crime studies fall somewhere in between these levels of apprehension. Thus as the level of enforcement rises to high enough levels, compliance should also rise.

Third, the evidence presented here that attitudes are minimally related to compliance should not be used to revise existing theories. The measures used in this study were a necessary but crude first attempt. When more refined measures exist, attitudes should be related to compliance when environment and enforcement are controlled.

\section{REFERENCES}

Anderson, James E. (1975). Public Policy-Making. New York: Praeger.

Bailey, John J., and Robert J. O'Connor (1975). “Operationalizing Incrementalism: Measuring the Muddles.' Public Administration Review 35: 60-66.

Boynton, G. R., Samuel C. Patterson, and Ronald Hedlund (1968). "The Structure of Public Support for Legislative Institutions." Midwest Journal of Political Science 12: 163-80.

Bullock, Charles S. III, and Harrell R. Rodgers Jr. (1976). "Coercion to Compliance." Journal of Politics 38: 987-1011.

California Highway Patrol (1974). Accident Changes Under Energy Crisis. Sacramento.

Castle, Gilbert H. III (1976). "The 55 Mph Speed Limit: A Cost/Benefit Analysis." Traffic Engineering, January 1976, 11-14.

The Challenge of Crime in a Free Society (1967). Washington, D.C.: Government Printing Office.

Clark, Jerry N., Keith O. Boyum, Samuel Krislov, and Roger C. Shaeffer (1972). "Compliance, Obedience and Revolt: An Overview." in Samuel Krislov et al., Compliance and the Law. Beverly Hills: Sage Publications. 
Comptroller General of the United States (1977). Speed Limit 55. Is it Achievable? Washington, D.C.: General Accounting Office.

Dahl, Robert (1956). A Preface to Democratic Theory. Chicago: University of Chicago Press.

Elazar, Daniel (1972). American Federalism: A View From the States. 2d ed. New York: Crowell.

Erickson, Maynard, and Jack P. Gibbs (1975). "Specific Versus General Properties of Legal Punishments and Deterrence." Social Science Quarterly 56: 390-97.

Etzioni, Amitai (1961). A Comparative Analysis of Complex Organizations. New York: The Free Press.

Gallup Opinion Index (1977). “Americans Want 55 Mgph Speed Limit Retained." Princeton, N.J., May 1977.

Jones, Terrance (1973). "Evaluating Everyday Policies: Police Activity and Crime Incidence," Urban Affairs Quarterly 8: 267-79.

Kim, Jae-on, John Petrocik, and Stephen Enokson (1975). "Voter Turnout Among American States." American Political Science Review 69: 107-23.

Logan, Charles H. (1975). “Arrest Rates and Deterrence." Social Science Quarterly 56: 376-89.

Rodgers, Harrell R., and Charles S. Bullock III (1976a). Coercion to Compliance. Lexington, Mass.: Lexington Books. (1976b). "School Desegregation." American Politics Quarterly 4: 153-76.

Salem, Richard G., and William J. Bowers (1972). "Severity of Formal Sanctions as a Deterrent to Deviant Behavior." In Samuel Krislov et al., Compliance and the Law. Beverly Hills: Sage Publications, pp. 313-32.

Sievers, John N. (1977). The 55 Mph Speed Limit: Public Attitudes and Opinions. Albuquerque: Institute for Applied Research Services, University of New Mexico.

Stover, Robert V., and Don W. Brown (1975). "Understanding Compliance and NonCompliance with the Law.' Social Science Quarterly 56: 363-75.

Tittle, Charles R., and Alan R. Rowe (1974). "Certainty of Arrest and Crime Rates.' Social Forces 52: 455-62.

Van Meter, Donald S., and Carl E. Van Horn (1975). "The Policy Implementation Process." 'Administration and Society 6: 445-88.

Wilson, James Q. (1973). Political Organizations. New York: Basic Books.

Young, Oran R. (1979). Compliance and Public Authority. Baltimore: Johns Hopkins Press. 